\title{
In Situ Synthesis and Photocatalytic Properties of Titanium Dioxide Nanoparticles on Cotton Fabrics
}

\author{
Zhanxia Bao $\cdot$ Shuhua Wang $\cdot$ Xiaoying Yu • \\ Yindong Gao $\cdot$ Zeling Wen
}

Received: 27 March 2019 / Accepted: 27 June 2019 / Published online: 9 July 2019

(C) Springer Nature Switzerland AG 2019

\begin{abstract}
In this paper, nanosized titanium dioxide as catalysts for degrading dye wastewater was in situ synthesized on the surface of cotton fabrics used tetrabutyl titanate as precursor. The morphology and structure of prepared catalysts were characterized by scanning electron microscopy, energy-dispersive spectrometer, and X-ray diffraction. The characterization results showed that anatase nanosized titanium dioxide was successfully synthesized in situ on cotton fabrics and had excellent dispersibility. Subsequently, the effects of irradiation time, catalyst dosage, dye concentration, initial $\mathrm{pH}$ value of dye, hydrogen peroxide dosage, and dye type on dye degradation rate were investigated one by one by a photocatalytic performance test. The test results indicated that the degradation rates of methylene blue, methyl orange, and rhodamine B were $90.4 \%, 81.4 \%$, and $58.3 \%$, separately, at catalyst dosage of $4.8 \mathrm{~g} / \mathrm{L}$, initial dye concentration of $10 \mathrm{mg} / \mathrm{L}, \mathrm{pH}$ of 7 , and hydrogen peroxide dosage of $0.24 \mathrm{~mol} / \mathrm{L}$, after $4 \mathrm{~h}$ of UV irradiation.
\end{abstract}

Highlights In this work, anatase nanosized titanium dioxide composite materials with high degradation performance to various types of dyes were prepared via an orthogonal design-oriented low-temperature calcination of waste cotton fabrics.

(1) The introduction of orthogonal experiment could be efficient, fast, and economical in optimizing experimental parameters.

(2) Titanium dioxide with high dispersibility could endow the cotton fabrics striking degradation performance to dyes.

(3) Recycling and reusing waste fabrics could be significant for relieving resource shortage, saving energy, and reducing emission.

Z. Bao $\cdot$ S. Wang $(\triangle) \cdot$ X. Yu $\cdot$ Y. Gao $\cdot$ Z. Wen College of Textile Engineering, Taiyuan University of Technology, Taiyuan 030600, People's Republic of China e-mail: wangshuhua@tyut.edu.cn
Keywords Dye wastewater. Tetrabutyl titanate Titanium dioxide $\cdot$ Cotton fabrics Photocatalytic performance $\cdot$ Degradation rate

\section{Introduction}

As a kind of semiconductor material with efficient photocatalytic activity, nanosized titanium dioxide (nano$\mathrm{TiO}_{2}$ ) possesses nontoxicity, high chemical stability, and excellent photocatalytic activity (Zhou et al. 2017; Goudarzi and Shahabi-Ghahfarrokhi 2018). Due to its attractive properties, nano- $\mathrm{TiO}_{2}$ could be widely applied in a variety of fields such as sterilization, air purification, and water treatment (Wang et al. 2015; Zhang et al. 2017). However, nano- $\mathrm{TiO}_{2}$ also has some disadvantages. First of all, the disadvantage of easy agglomeration of nano- $\mathrm{TiO}_{2}$ greatly limits its performance. Due to the large specific surface area and high surface energy of pure nano- $\mathrm{TiO}_{2}$ particles, which belong to thermodynamic unstable systems, the surface particles cluster together with each other due to van der Waals force and Coulomb force, so that the nano- $\mathrm{TiO}_{2}$ particles are agglomerated and lose the physical properties and functions when applied. Therefore, it is imperative to prepare highly dispersed nano- $\mathrm{TiO}_{2}$ to maintain its advantages in photocatalytic performance. Secondly, nano- $\mathrm{TiO}_{2}$ particles in the water system are easy to lose, difficult to recycle, and high in recycling cost (Liu et al. 2018). Therefore, it is necessary to find a suitable carrier to immobilize nano- $\mathrm{TiO}_{2}$ for recycling. In order to solve 
the above problems, many scholars have extensively studied supported nano- $\mathrm{TiO}_{2}$ photocatalysts.

At present, the carrier materials commonly loading nano$\mathrm{TiO}_{2}$ mainly include silicas (Sosnov et al. 2017), polymers (Vukoje et al. 2016), glasses (Yusoff et al. 2016), and carbon materials (Das et al. 2018; Xu et al. 2016a, b; Liang et al. 2018). All these materials have the characteristics of good stability, high strength, large specific surface area, and firm load. Because of large surface area, interwoven network structure of yarns, inherent strength, and flexibility, the cotton fabrics (CFs) can provide a good bearing platform for nano- $\mathrm{TiO}_{2}$, which is conducive to the formation of highly dispersed $\mathrm{TiO}_{2}$, thus maximizing its dye degradation performance. At the same time, $\mathrm{TiO}_{2}$ also provides a choice to impart multifunctional properties of the CFs (Mishra and Butola 2017; Giesz et al. 2016).

The annual output of waste CFs is huge, and they cannot be used reasonably, which will not only pollute the environment but also waste resources greatly (Pensupa et al. 2017). Therefore, using CFs as the carrier of $\mathrm{TiO}_{2}$ not only has a wide source and low cost but also protects the environment and makes effective utilization of resources (Ma et al. 2018). As reported by Giesz et al., using the methods of sol-gel process and microwave treatment successfully prepared $\mathrm{TiO}_{2}$-anatase film on cotton and viscose fabric surfaces (Giesz et al. 2016).

In this work, nano- $\mathrm{TiO}_{2}$ synthesized in situ and loaded on CFs was successfully prepared by using a hydrothermal method and low-temperature calcination, with cheap and readily available CFs as carrier and tetrabutyl titanate (TBT) as raw material. The loaded nano- $\mathrm{TiO}_{2}$ had anatase crystal form, high dispersion, and superior catalytic activity.

\section{Experiments}

\subsection{Raw Materials and Reagents}

CFs were used as substrate for loading nano- $\mathrm{TiO}_{2}$. Nano- $\mathrm{TiO}_{2}$ was prepared from TBT as raw material. The dyes, methylene blue (MB), methyl orange (MO), and rhodamine $\mathrm{B}(\mathrm{RhB})$ are all of analytical reagent (AR) grade and are commercially available.

\subsection{Preparation of Loaded- $\mathrm{TiO}_{2}$ Cotton Fabrics $\left(\mathrm{TiO}_{2} /\right.$ $\mathrm{CFs})$}

According to the analysis of this experiment, there are many factors affecting photocatalytic degradation rate, such as hydrolysis temperature, hydrolysis time, hydrothermal temperature, hydrothermal time, calcination temperature, calcination time, dye type, dye concentration, solution $\mathrm{pH}$ value, illumination time, illumination intensity, and hydrogen peroxide $\left(\mathrm{H}_{2} \mathrm{O}_{2}\right)$ dosage. After comprehensive consideration, the hydrolysis temperature, hydrothermal temperature, hydrothermal time, and calcination time were determined as the experimental factors for the preparation of the experiment and were marked as $A, B, C$, and $D$, respectively. Three-level and four-factor orthogonal experiments were carried out. The factors and levels are shown in Table 1.

The specific preparation process of the experiment was as follows: $1.6 \mathrm{~g} \mathrm{CFs}$ were immersed in $8 \mathrm{~mL}$ TBT for $24 \mathrm{~h}$ at room temperature, followed by taking out the CFs and squeezing away as much liquid as possible from the surface of the CFs. Then, loaded TBT CFs were quickly immersed into $20 \mathrm{~mL}$ deionized water to hydrolyze for $30 \mathrm{~min}$. Subsequently, it was transferred to a polytetrafluoroethylene autoclave for hydrothermal treatment. After a certain period of time, the products were poured into a beaker, washed three times with deionized water (to remove unloaded or not firmly loaded $\mathrm{TiO}_{2}$ particles from the CFs surface), and dried at $60{ }^{\circ} \mathrm{C}$. Finally, the products were calcined at $200^{\circ} \mathrm{C}$ and cooled to obtain $\mathrm{TiO}_{2} /$ CFs. A simulation of the preparation process is shown in Fig. 1.

2.3 Photocatalytic Degradation of MB, MO, and RhB under UV Irradiation

$\mathrm{MB}, \mathrm{MO}$, and $\mathrm{RhB}$ were selected as model chemicals to evaluate the photocatalytic performance of $\mathrm{TiO}_{2} / \mathrm{CFs}$. About $0.30 \mathrm{~g}$ of $\mathrm{TiO}_{2} / \mathrm{CFs}$ was placed separately in $60 \mathrm{~mL}$ of $\mathrm{MB}, \mathrm{MO}$, and $\mathrm{RhB}$ solution $(10 \mathrm{mg} / \mathrm{L})$. Before irradiation, these solutions were stirred $(500 \mathrm{r} / \mathrm{min})$ in the dark for $30 \mathrm{~min}$ to achieve the adsorption equilibrium (Wu and Long 2011). Then, they were exposed to UV radiation with the wavelength of $365 \mathrm{~nm}$ (UV-365) maintaining

Table 1 Factors and levels of orthogonal design

\begin{tabular}{lcccc}
\hline Levels & \multicolumn{4}{l}{ Experimental factors } \\
\cline { 2 - 5 } & $A /{ }^{\circ} \mathrm{C}$ & $B /{ }^{\circ} \mathrm{C}$ & $C / \mathrm{h}$ & $D / \mathrm{h}$ \\
\hline 1 & 60 & 120 & 6 & 2 \\
2 & 80 & 150 & 8 & 3 \\
3 & 100 & 180 & 10 & 4 \\
\hline
\end{tabular}




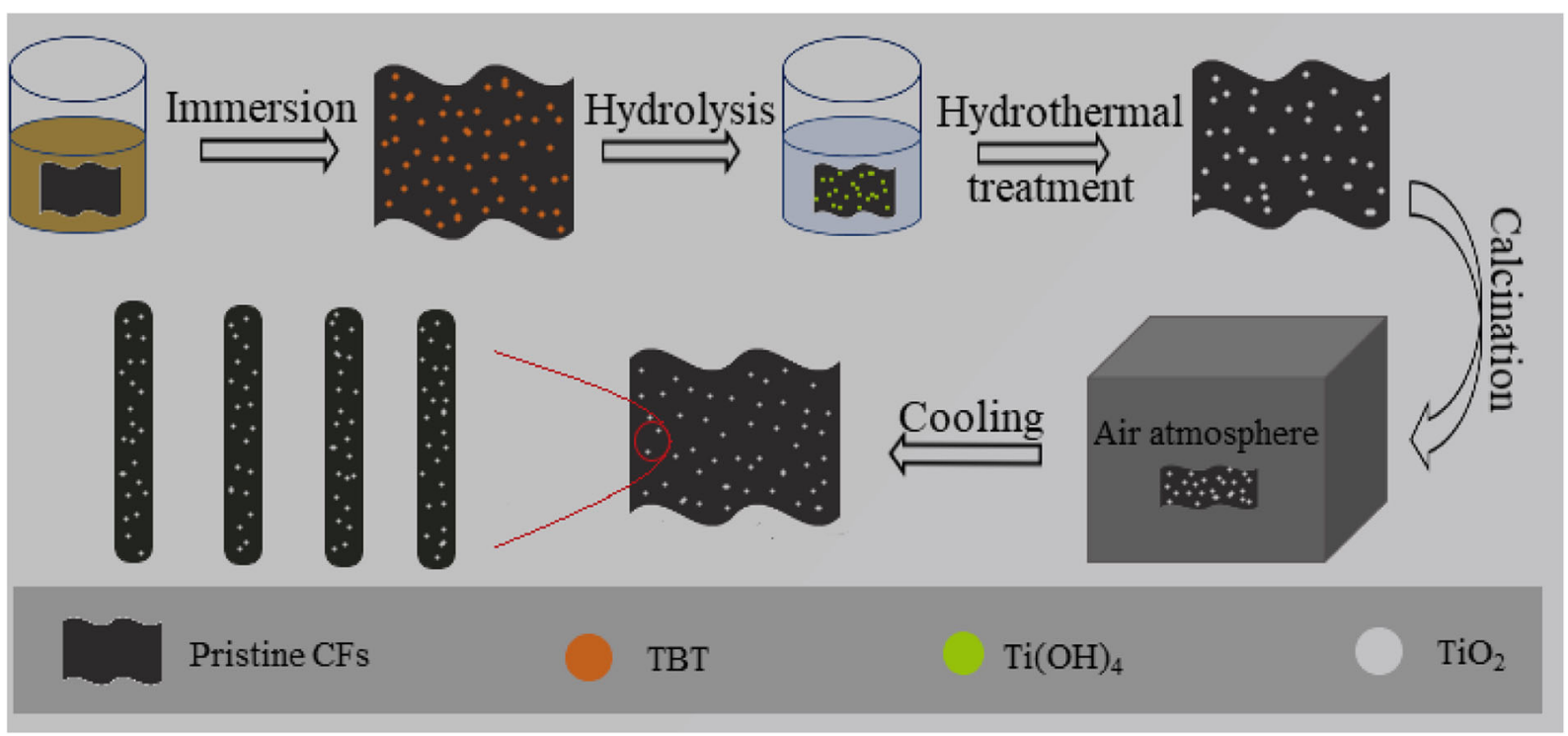

Fig. 1 The preparation of $\mathrm{TiO}_{2} / \mathrm{CFs}$

vigorous stirring (500 r/min). The $\mathrm{MB}, \mathrm{MO}$, and $\mathrm{RhB}$ solutions were taken out at regular intervals, and the absorbances were measured by a 721 visible spectrophotometer, at the maximum absorption wavelength of $664 \mathrm{~nm}$ (Phaltane et al. 2017), $464 \mathrm{~nm}$ (John et al. 2017), and $552 \mathrm{~nm}$ (Cai et al. 2018), respectively. Before measuring, the suspensions were filtered through an organic micropore filter (pore size $0.45 \mu \mathrm{m}$ ). Taking MB solution as an example, since the $\mathrm{MB}$ solution concentration $\mathrm{C}(\mathrm{mg} / \mathrm{L})$ was proportional to the absorbance within a certain range as shown in Fig. 2, it could be approximately expressed as (Eq. (1)):

$A=0.12057 \mathrm{C}, R^{2}=0.99883$.

Therefore, the degradation rate $D(\%)$ could be calculated by replacing the concentration $C$ with the absorbance $A$. Eventually, the degradation rate was calculated by the measured absorbance as follows (Eq. (2)) (Zhang and Yang 2012):

$D=\left[\left(A_{0}-A_{t}\right) / A_{0}\right] \times 100 \%$

where $A_{0}$ is the absorbance of the MB solution after dark reaction for $30 \mathrm{~min} ; A_{t}$ is the absorbance of the MB solution irradiated for $t$.

\section{Results and Discussions}

\subsection{Orthogonal Test}

This experiment was a three-level and four-factor test, where only the effect of the four factors on the degradation rate was considered, ignorance of the interactions among the factors. Therefore, $L_{9}$ $\left(3^{4}\right)$ orthogonal table should be selected. The specific test conditions and results are shown in Table 2. The degradation rates of $\mathrm{MB}$ evaluated and recorded as $D_{\mathrm{MB}}$, as the final evaluation index.

As shown in Table 2, the orders for the average values $(-K)$ of each factor were as follows: $K_{A 2}>^{-} K_{A 1}>^{-} K_{A 3},{ }^{-} K_{B 2}>^{-} K_{B 1}>^{-} K_{B 3},{ }^{-} K_{C 3}>^{-}$ $K_{C 1}>^{-} K_{C 2}$, and ${ }^{-} K_{D 1}>^{-} K_{D 3}>^{-} K_{D 2}$. Therefore, $A_{2}, B_{2}, C_{3}$, and $D_{1}$ could be determined as the optimal levels of factors $A, B, C$, and $D$, respectively. The combination of $A_{2} B_{2} C_{3} D_{1}$ was the optimal level combination in this experiment. This meant that the optimal preparation conditions were hydrolysis temperature $80{ }^{\circ} \mathrm{C}$, hydrothermal temperature $150{ }^{\circ} \mathrm{C}$, hydrothermal time $10 \mathrm{~h}$, and calcination time $2 \mathrm{~h}$. The range $(R)$ calculation demonstrated that $R_{B}>R_{D}>R_{A}>R_{C}$. Hence, for $\mathrm{MB}$, the greatest influence was hydrothermal temperature, followed by calcination time and hydrolysis temperature, while hydrothermal time was the least influence. 


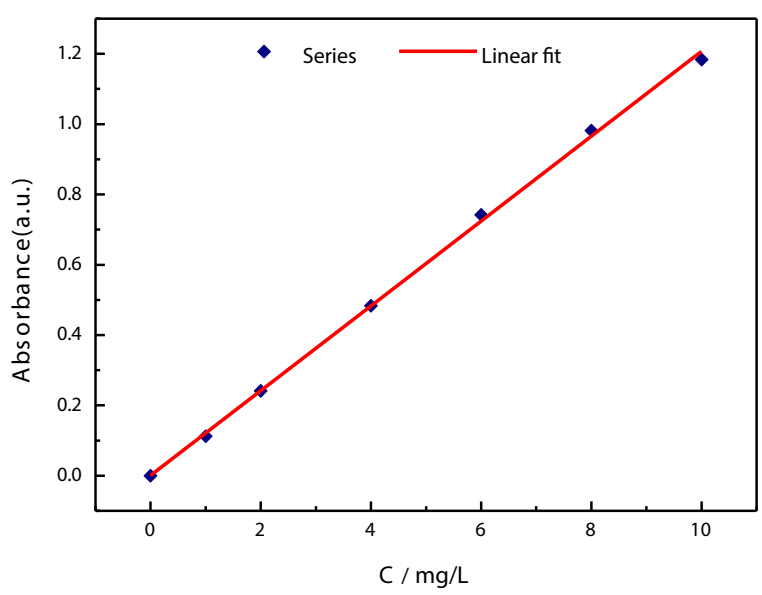

Fig. 2 Standard working curve of MB solution

\subsection{Characterization of Morphology and Structure}

\subsubsection{Scanning Electron Microscopy and Energy-Dispersive Spectrometer}

Scanning electron microscopy (SEM) was used to characterize the surface morphology of the samples and the distribution of $\mathrm{TiO}_{2}$ particles on CFs as shown in Fig. 3. The chemical composition of $\mathrm{TiO}_{2} / \mathrm{CFs}$ was characterized by energy-dispersive spectrometer (EDS) as shown in Fig. 4.

Table 2 Specific test conditions and results

\begin{tabular}{lccccc}
\hline Sample & $A\left({ }^{\circ} \mathrm{C}\right)$ & $B\left({ }^{\circ} \mathrm{C}\right)$ & $C(\mathrm{~h})$ & $D(\mathrm{~h})$ & $D_{\mathrm{MB}}(\%)$ \\
\hline 1 & 60 & 120 & 6 & 2 & 30.8 \\
2 & 60 & 150 & 8 & 3 & 32.3 \\
3 & 60 & 180 & 10 & 4 & 26.3 \\
4 & 80 & 120 & 8 & 4 & 29.4 \\
5 & 80 & 150 & 10 & 2 & 37.7 \\
6 & 80 & 180 & 6 & 3 & 24.8 \\
7 & 100 & 120 & 10 & 3 & 27.3 \\
8 & 100 & 150 & 6 & 4 & 32.3 \\
9 & 100 & 180 & 8 & 2 & 25.4 \\
$K_{1}$ & 89.4 & 87.5 & 87.9 & 93.9 & \\
$K_{2}$ & 91.9 & 102.3 & 87.1 & 84.4 & \\
$K_{3}$ & 85.0 & 76.5 & 91.3 & 88.0 & \\
$-K_{1}$ & 29.8 & 29.2 & 29.3 & 31.3 & \\
$-K_{2}$ & 30.6 & 34.1 & 29.0 & 28.1 & \\
$-K_{3}$ & 28.3 & 25.5 & 30.4 & 29.3 & \\
$R$ & 2.3 & 8.6 & 1.4 & 3.2 & \\
\hline
\end{tabular}

Figure $3 \mathrm{a}$ is a SEM image of the original CFs, from which it could be observed that the surface had a small amount of natural impurities and warp (Yang et al. 2019), so it had a certain roughness and was beneficial to the loading of $\mathrm{TiO}_{2}$. Figure $3 \mathrm{~b}$ is a SEM image of $\mathrm{TiO}_{2} / \mathrm{CFs}$, from which it could be observed that $\mathrm{CFs}$ still maintained its original shape, and $\mathrm{TiO}_{2}$ was uniformly and firmly distributed on the surface of the CFs. This was because there were many free hydroxyl groups on the surface of $\mathrm{CFs}$, which could react with hydroxyl radicals $(\cdot \mathrm{OH})$ on the surface of $\mathrm{TiO}_{2}$, so the combination between them was strong enough. Through EDS energy spectrum analysis, it could be found that the prepared $\mathrm{TiO}_{2} / \mathrm{CFs}$ contained $\mathrm{C}$, Ti, and $\mathrm{O}$ elements, which further confirmed the in situ synthesis of $\mathrm{TiO}_{2}$ on $\mathrm{CFs}$.

\subsubsection{X-Ray Diffraction}

$\mathrm{X}$-ray diffraction (XRD) was carried out to determine the crystal structure (brookite, anatase, or rutile) of $\mathrm{TiO}_{2}$ particles on $\mathrm{CFs}$ at $2 \theta$ from $10^{\circ}$ to $70^{\circ}$ with $\mathrm{Cu} \mathrm{K} \alpha$ radiation, as shown in Fig. 5. Figure 5a showed the XRD pattern of the pristine CFs as blank samples, from which only the characteristic peaks of CFs were observed. Figure $5 \mathrm{~b}$ shows the XRD pattern of the prepared $\mathrm{TiO}_{2} / \mathrm{CFs}$, from which not only the characteristic diffraction peaks $15.6^{\circ}, 16.8^{\circ}$, and $23.1^{\circ}$ of CFs but also the characteristic diffraction peaks $25.6^{\circ}, 38.2^{\circ}, 48.2^{\circ}$, $54.3^{\circ}$, and $62.2^{\circ}$ of typical anatase $\mathrm{TiO}_{2}$ were observed, corresponding to the crystal faces of (101), (112), (200), (211), and (204) (Sun et al. 2000; Zhou et al. 2017). In addition, using the XRD diffraction pattern of Fig. 4b, the crystallite diameter $(D)$ of anatase $\mathrm{TiO}_{2}$ crystal was calculated based on (101) crystal face reflection according to the Scherer formula (Eq. (3)) (Kinsinger et al. 2011; Sun et al. 2000):

$D=k \lambda /(\beta \cos \theta)$

where $k$ is the shape constant (typical around 0.9) (Tang et al. 2009), $\lambda$ is the wavelength of the $\mathrm{Cu} \mathrm{K} \alpha$ radiation $(\lambda=0.154 \mathrm{~nm}), \beta$ is the full width at half maximum (FWHM), and $\theta$ is the diffraction angle. The $\mathrm{TiO}_{2}$ particle size was about $9.4 \mathrm{~nm}$. Therefore, $\mathrm{TiO}_{2}$ was a nanosized particle.

From above, it could be determined that in situ synthesis of anatase nano- $\mathrm{TiO}_{2}$ particles on CFs could be achieved by the hydrothermal method and lowtemperature $\left(200{ }^{\circ} \mathrm{C}\right)$ calcination. Therefore, in order 


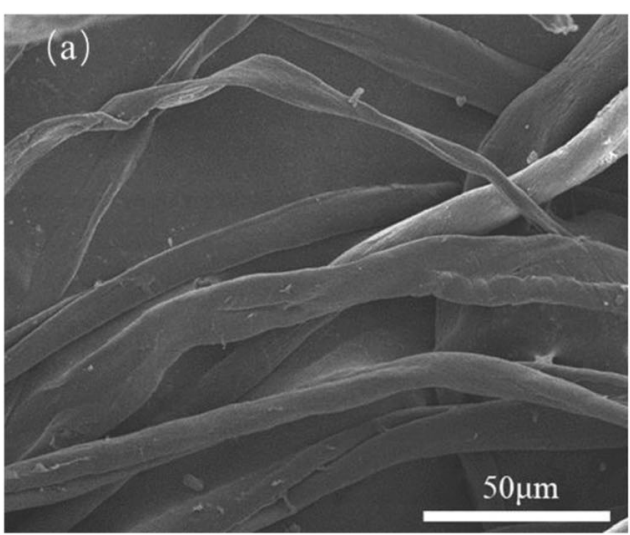

Fig. 3 SEM images of the two samples. a Pristine $\mathrm{CFs}$. b $\mathrm{TiO}_{2} / \mathrm{CFs}$

to make use of the photocatalytic properties of nano$\mathrm{TiO}_{2}$, the prepared $\mathrm{TiO}_{2} / \mathrm{CFs}$ would be used in the research of dye-simulated wastewater treatment in the subsequent work.

\subsection{Photocatalytic Degradation Performance}

\subsubsection{Effects of UV Irradiation Time on Photocatalytic Activity}

Figure 6 shows the effects of irradiation time on photocatalytic performance of $\mathrm{TiO}_{2} / \mathrm{CFs}$ under the conditions of UV-365 irradiation, MB solution concentration of $10 \mathrm{mg} / \mathrm{L}$, and $\mathrm{TiO}_{2} / \mathrm{CFs}$ dosage of $4.8 \mathrm{~g} / \mathrm{L}$. As can be seen from Fig. 6, the degradation rate of pristine CFs to MB solution in $9 \mathrm{~h}$ under UV-365 irradiation was about

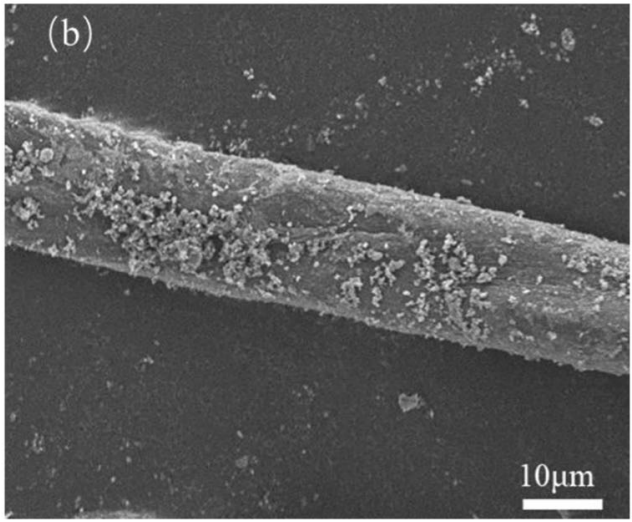

$15 \%$, which was basically negligible in comparison with the higher degradation rate of $\mathrm{TiO}_{2} / \mathrm{CFs}$. For $\mathrm{TiO}_{2} / \mathrm{CFs}$, the degradation efficiency of $\mathrm{MB}$ solution gradually decreased with the increase of irradiation time, but the degradation rate gradually increased. This was because the intermediate products produced in the process of $\mathrm{MB}$ degradation occupied the active parts of $\mathrm{TiO}_{2}$, and a competition for degradation may occur between the $\mathrm{MB}$ and the intermediate products (Rauf et al. 2011), resulting in a decrease in degradation efficiency. Especially after $5 \mathrm{~h}$, the degradation efficiency of MB solution was only $1.6 \%$. However, with the gradual reaction of intermediate products and the continuous adsorption and degradation of $\mathrm{MB}$ solution, the degradation rate showed an increasing trend. However, after $5 \mathrm{~h}$, the degradation rate also tended to be basically balanced.
Fig. 4 EDS energy spectrum of $\mathrm{TiO}_{2} / \mathrm{CFs}$

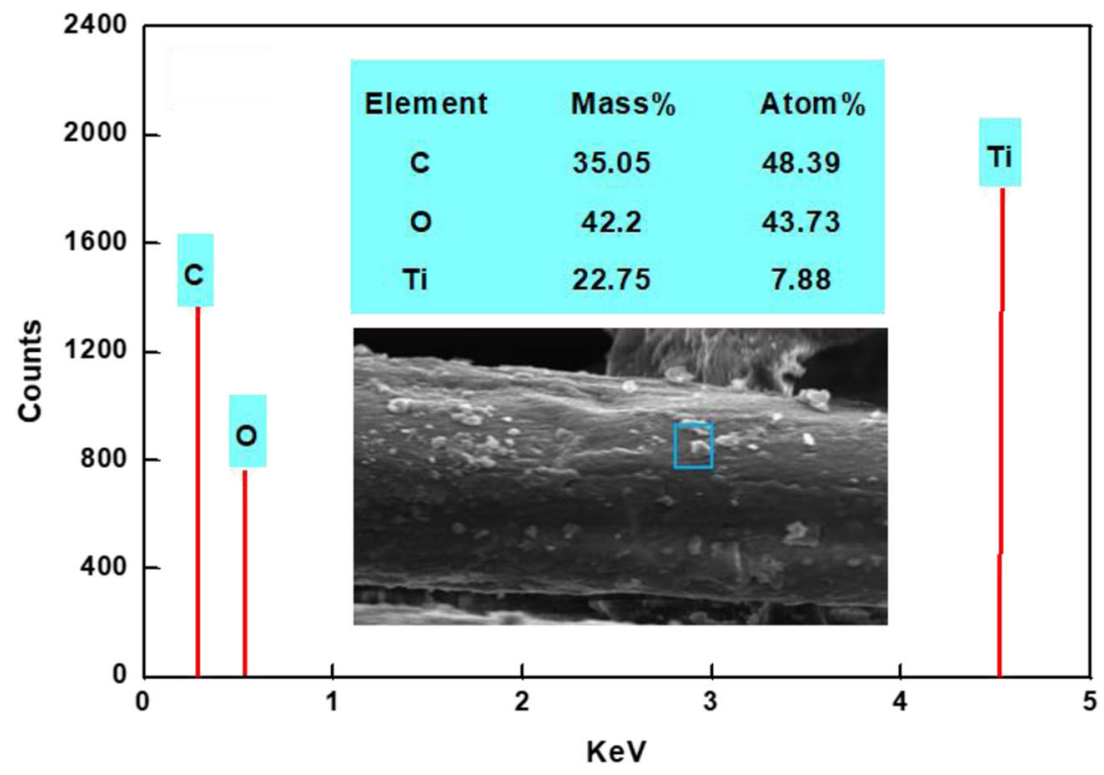


Fig. 5 The XRD patterns of the samples. a Pristine CFs. b $\mathrm{TiO}_{2} /$ CFs
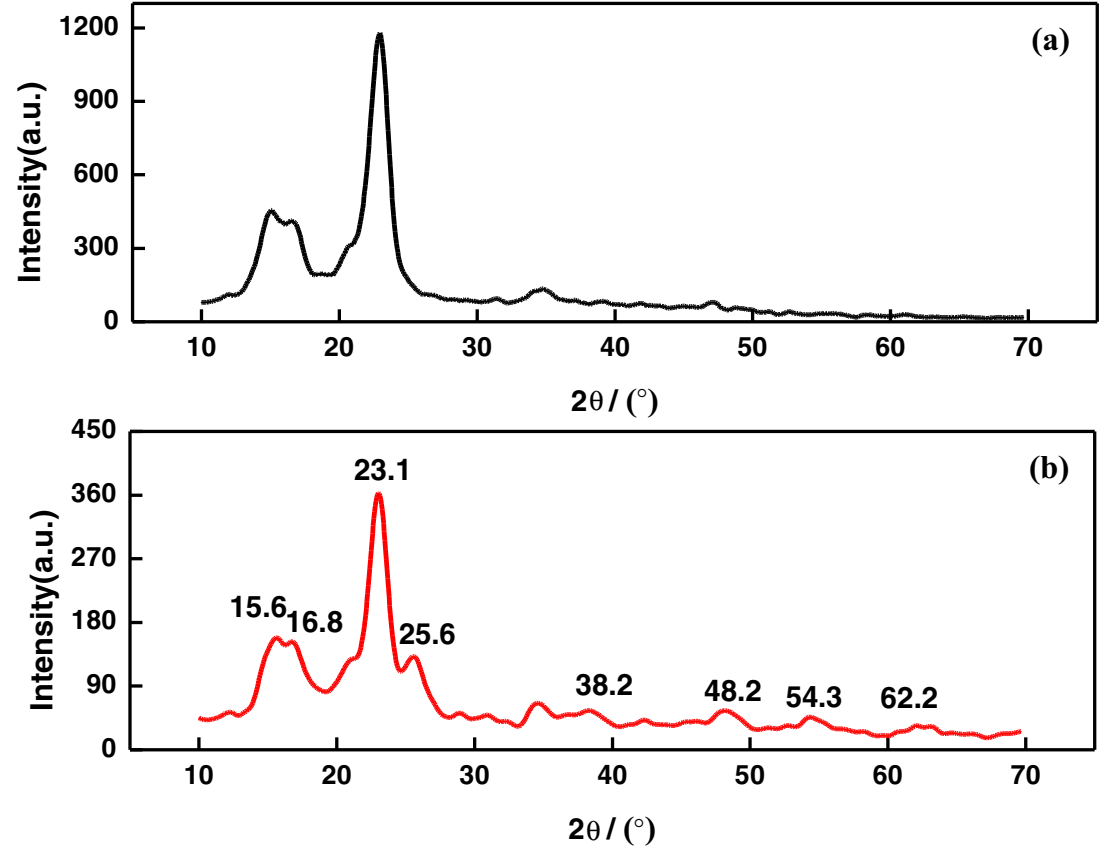

\subsubsection{Effects of $\mathrm{TiO}_{2} / \mathrm{CFS}$ Dosage on Photocatalytic Activity}

Figure 7 reveals the effects of $\mathrm{TiO}_{2} / \mathrm{CFs}$ dosage on photocatalytic performance of $\mathrm{TiO}_{2} / \mathrm{CFs}$ under the conditions of UV-365 irradiation for $5 \mathrm{~h}$ and $\mathrm{MB}$ solution concentration of $10 \mathrm{mg} / \mathrm{L}$. When the dosage of $\mathrm{TiO}_{2} / \mathrm{CFs}$ was less than $4.8 \mathrm{~g} / \mathrm{L}$, the degradation rate of $\mathrm{MB}$ solution increased with the increase of $\mathrm{TiO}_{2} / \mathrm{CFs}$. This was because the more $\mathrm{TiO}_{2} /$ CFs could provide, the more active sites there are and the more dyes could be adsorbed and degraded. However,

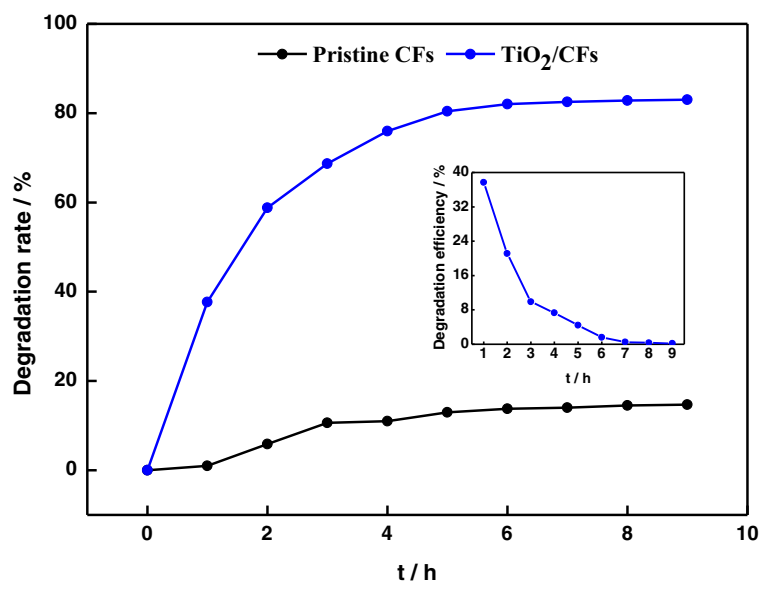

Fig. 6 The effects of illumination time on degradation rate of MB solution under UV-365 when the dosage of $\mathrm{TiO}_{2} / \mathrm{CFs}$ exceeded $4.8 \mathrm{~g} / \mathrm{L}$, the degradation rate of $\mathrm{MB}$ solution did not significantly increase with the addition of $\mathrm{TiO}_{2} / \mathrm{CFs}$. This was because the presence of excess $\mathrm{TiO}_{2} / \mathrm{CFs}$ would lead to a decrease in light transmittance, thus limiting the irradiated areas of $\mathrm{TiO}_{2} / \mathrm{CFs}$. Therefore, for this experiment, the optimum dosage of $\mathrm{TiO}_{2} / \mathrm{CFs}$ was $4.8 \mathrm{~g} / \mathrm{L}$.

\subsubsection{Effects of Dye Concentration on Photocatalytic Activity}

Figure 8 displays the effects of $\mathrm{MB}$ concentration on photocatalytic performance of $\mathrm{TiO}_{2} / \mathrm{CFs}$ under the conditions of UV-365 irradiation for $5 \mathrm{~h}$ and $\mathrm{TiO}_{2} / \mathrm{CFs}$ dosage of $4.8 \mathrm{~g} / \mathrm{L}$. As can be seen from Fig. 8, the degradation rate of $\mathrm{MB}$ solution decreased with the increase of initial concentration of MB solution. The reason was that when the concentration of MB solution was relatively low, the number of dyes in the solution was relatively small, so there were relatively few dyes migrating and enriching to the $\mathrm{TiO}_{2} / \mathrm{CFs}$ surface. However, there were relatively many active sites on the surface of $\mathrm{TiO}_{2} / \mathrm{CFs}$, and fewer dyes were not enough to enable all active sites of $\mathrm{TiO}_{2} / \mathrm{CFs}$ to exert the catalytic ability. When the concentration of $\mathrm{MB}$ solution was $5 \mathrm{mg} / \mathrm{L}$, the degradation rate of $\mathrm{TiO}_{2} / \mathrm{CFs}$ to $\mathrm{MB}$ solution was the highest, reaching $98 \%$. With the increase of MB solution concentration, the amount of $\mathrm{MB}$ 


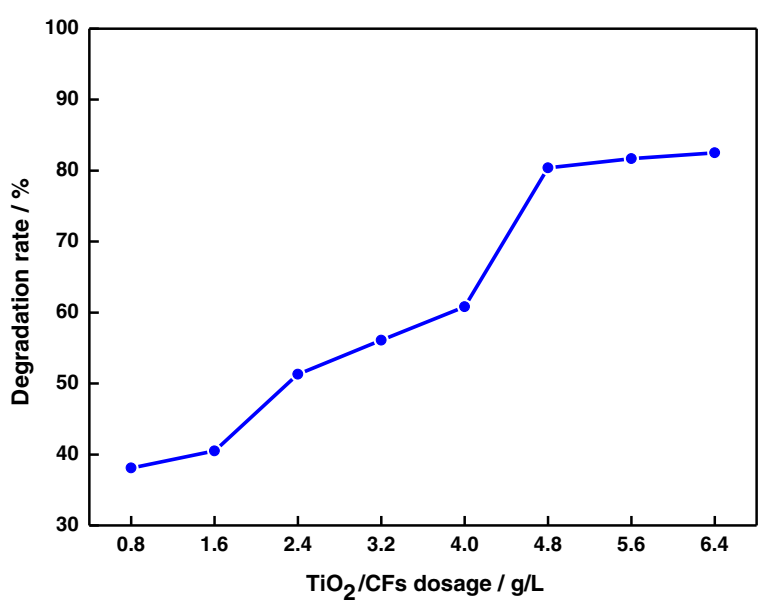

Fig. 7 The effects of $\mathrm{TiO}_{2} / \mathrm{CFs}$ dosage on degradation rate of $\mathrm{MB}$ solution

adsorbed on the $\mathrm{TiO}_{2} / \mathrm{CFs}$ surface gradually reached saturation, and the catalytic capacity also reached maximum. In addition, intermediate products that were difficult to decompose would also accumulate around $\mathrm{TiO}_{2} / \mathrm{CFs}$ due to lack of time for reaction, hindering the progress of photocatalytic reaction. Therefore, the prepared $\mathrm{TiO}_{2} / \mathrm{CFs}$ were suitable for the degradation of low concentration dyes $(5 \mathrm{mg} / \mathrm{L}, 10 \mathrm{mg} / \mathrm{L}$, and $15 \mathrm{mg} /$ L).

\subsubsection{Effects of pH Value on Photocatalytic Activity}

Figure 9 describes the effects of initial $\mathrm{pH}$ value on photocatalytic performance of $\mathrm{TiO}_{2} / \mathrm{CFs}$ under the

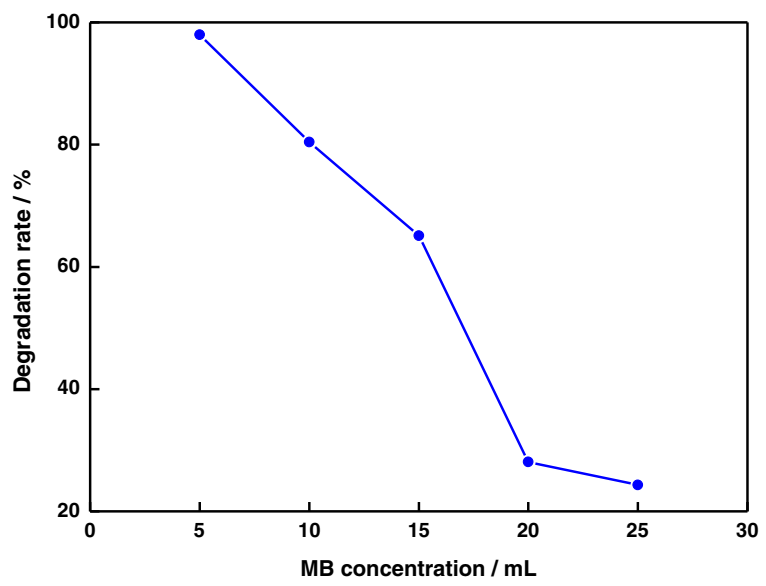

Fig. 8 The effects of dye concentration on degradation rate of MB solution

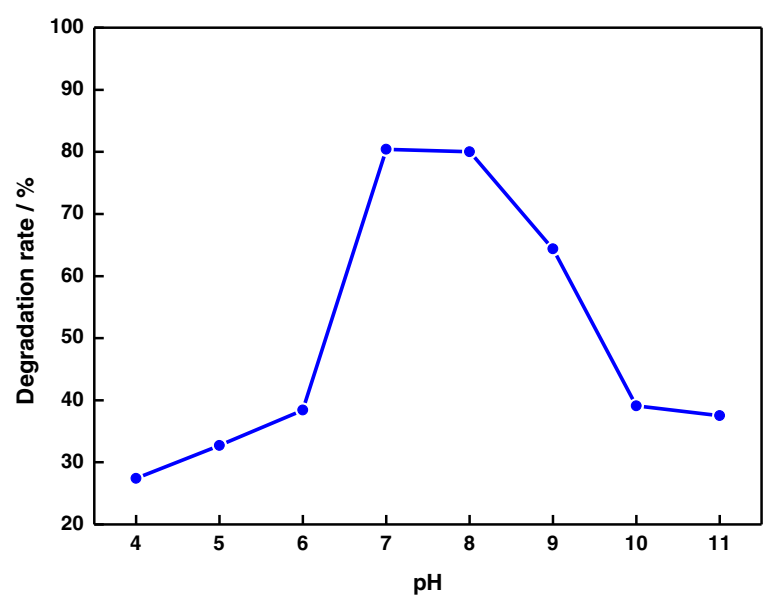

Fig. 9 The effects of the initial $\mathrm{pH}$ value on degradation rate of MB solution

conditions of UV-365 irradiation for $5 \mathrm{~h}, \mathrm{TiO}_{2} / \mathrm{CFs}$ dosage of $4.8 \mathrm{~g} / \mathrm{L}$, and $\mathrm{MB}$ concentration of $10 \mathrm{mg} / \mathrm{L}$. It could be seen that the degradation of $\mathrm{MB}$ by $\mathrm{TiO}_{2} / \mathrm{CFs}$ first increased and then decreased with the increase of $\mathrm{pH}$ value in the $\mathrm{pH}$ range of 4.0-11.0. The isoelectric point of $\mathrm{TiO}_{2}$ in water was about $\mathrm{pH}=6.0$ (Devipriya and Yesodharan 2010), which meant that the surface of $\mathrm{TiO}_{2}$ was neutral. When the solution was $\mathrm{pH}<6.0$, the $\mathrm{TiO}_{2}$ surface had a net positive charge, as shown in Eq. (4) (Kaur et al. 2018). Because MB was a cationic dye, the existence of $\mathrm{TiOH}_{2}{ }^{+}$was not conducive to the adsorption of $\mathrm{MB}$ by $\mathrm{TiO}_{2} / \mathrm{CFs}$. So, the degradation of $\mathrm{MB}$ by $\mathrm{TiO}_{2} / \mathrm{CFs}$ was obviously inhibited under acidic conditions. When the solution was $\mathrm{pH}>6.0$, the $\mathrm{TiO}_{2}$ surface carried a net negative charge, as shown in Eq. (5)

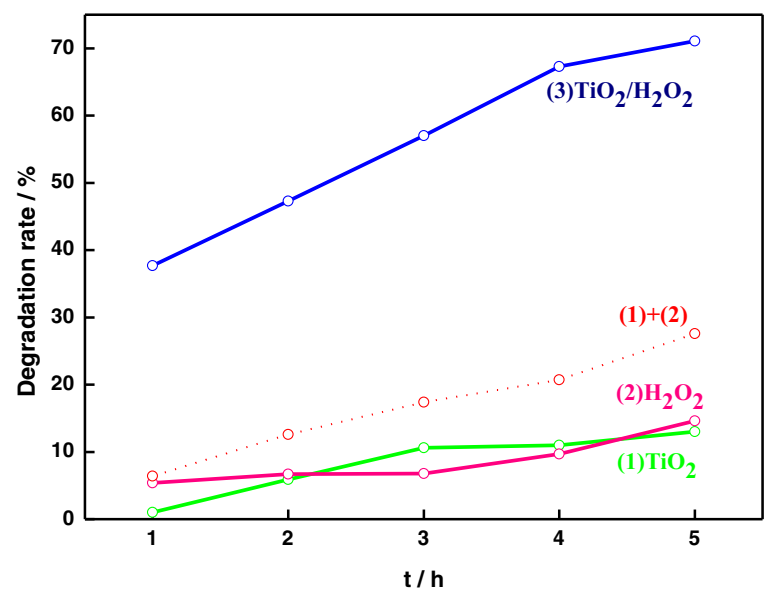

Fig. 10 The degradation rate of MB solution under different conditions 
(Kaur et al. 2018). This was also conducive to the migration of holes to the surface of $\mathrm{TiO}_{2}$ and the formation of $\cdot \mathrm{OH}$ with strong oxidation by reacting with $\mathrm{OH}^{-}$, $\mathrm{H}_{2} \mathrm{O}$, and other electron donors on the surface of $\mathrm{TiO}_{2}$. In addition, $\mathrm{TiO}_{2}$ was negatively charged in neutral and weakly alkaline solutions and electrostatically adsorbed MB cations (Azeez et al. 2018), thus greatly increasing the degradation of MB. Particularly, when the solution was $\mathrm{pH}=7.0$, the degradation rate of $\mathrm{MB}$ was the highest, up to $80.4 \%$.

$\mathrm{TiOH}+\mathrm{H}^{+} \rightarrow \mathrm{TiOH}_{2}{ }^{+}(\mathrm{pH}<6.0)$

$\mathrm{TiOH}+\mathrm{OH}^{-} \rightarrow \mathrm{TiO}^{-}+\mathrm{H}_{2} \mathrm{O}(\mathrm{pH}>6.0)$

However, when the $\mathrm{pH}$ the solution was $\mathrm{pH}>9.0$, the degradation rate of $\mathrm{MB}$ solution decreased significantly. To sum up, $\mathrm{TiO}_{2} / \mathrm{CFs}$ was more beneficial to the degradation of MB under neutral or weakly alkaline conditions. Since the $\mathrm{pH}$ value of $\mathrm{MB}$ solution itself was about 7 , there was no need to adjust the $\mathrm{pH}$ value later.

\subsubsection{Effects of $\mathrm{H}_{2} \mathrm{O}_{2}$ Dosage on Photocatalytic Activity}

As a kind of strong oxidative reagent and electron scavenger, the dosage of $\mathrm{H}_{2} \mathrm{O}_{2}$ is considered to be an important parameter affecting the photocatalytic degradation process because it is directly related to the amount of $\cdot \mathrm{OH}$ generated in the photocatalytic reaction.

First of all, in order to prove that $\mathrm{H}_{2} \mathrm{O}_{2}$ could promote $\mathrm{TiO}_{2}$ to degrade dyes, three experiments were designed as shown in Fig. 10. The curve (1) showed the degradation rate of MB solution only in the presence of $\mathrm{TiO}_{2} /$ CFs. The curve (2) showed the degradation rate of MB solution only in the presence of $\mathrm{H}_{2} \mathrm{O}_{2}$. The dashed line $(1)+(2)$ was the sum of the degradation rates of $\mathrm{MB}$ solution under conditions (1) and (2) alone. The curve (3) showed the degradation of MB solution in the presence of $\mathrm{TiO}_{2} / \mathrm{CFs}$ and $\mathrm{H}_{2} \mathrm{O}_{2}$. As can be seen from Fig. 11, the degradation rate was obviously (3) $>(1)+$ (2). Therefore, it came to a conclusion that $\mathrm{H}_{2} \mathrm{O}_{2}$ could promote $\mathrm{TiO}_{2}$ to degrade dyes.

Subsequently, the effects of $\mathrm{H}_{2} \mathrm{O}_{2}$ dosage on photocatalytic performance of $\mathrm{TiO}_{2} / \mathrm{CFs}$ under the conditions of UV-365 irradiation for $2 \mathrm{~h}$ and $4 \mathrm{~h}, \mathrm{TiO}_{2} / \mathrm{CFs}$ dosage of $4.8 \mathrm{~g} / \mathrm{L}, \mathrm{MB}$ concentration of $10 \mathrm{mg} / \mathrm{L}$, and initial $\mathrm{pH}$ value of 7 were discussed, as shown in Fig. 11.

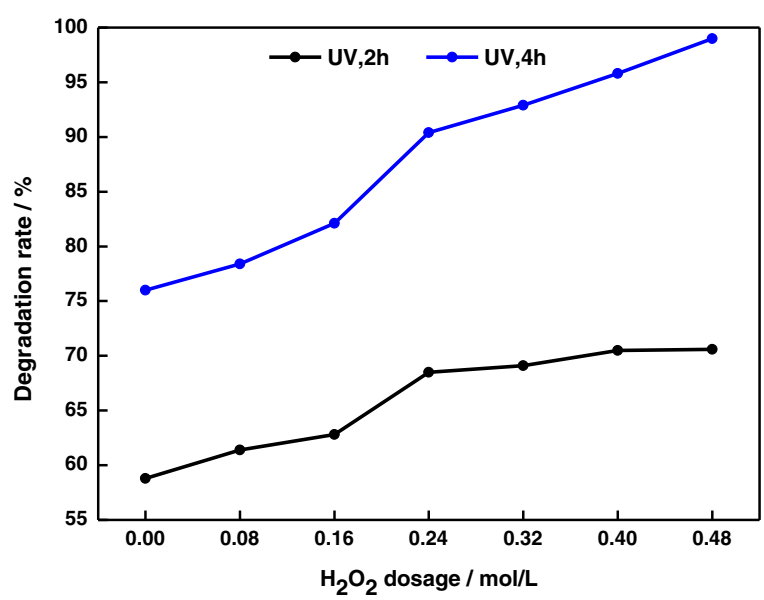

Fig. 11 The effects of $\mathrm{H}_{2} \mathrm{O}_{2}$ dosage on degradation rate of $\mathrm{MB}$ solution

According to the curve of illumination for $2 \mathrm{~h}$ (sealed), it could be concluded that in the presence of $\mathrm{H}_{2} \mathrm{O}_{2}$, the degradation rate of $\mathrm{MB}$ solution first increased and then tended to be stable with the increase of $\mathrm{H}_{2} \mathrm{O}_{2}$ dosage; the degradation efficiency of $\mathrm{MB}$ solution was the highest when $0.24 \mathrm{~mol} / \mathrm{L} \mathrm{H}_{2} \mathrm{O}_{2}$ was added to $60 \mathrm{~mL} \mathrm{MB}$ solution. This was because when the dosage of added $\mathrm{H}_{2} \mathrm{O}_{2}$ was less than $0.24 \mathrm{~mol} / \mathrm{L}, \mathrm{H}_{2} \mathrm{O}_{2}$ could capture electrons on the surface of $\mathrm{TiO}_{2}$ (Eq. (6)), thus reducing the probability of electron-hole recombination and improving hole utilization (Eq. (7) and Eq. (8)) (Akpan and Hameed 2009). In addition, $\mathrm{H}_{2} \mathrm{O}_{2}$ may be decomposed directly to generate $\cdot \mathrm{OH}$ under UV irradiation (Eq. (9)) (Navarro et al. 2005), which was the strongest oxidant in aqueous phase systems and could degrade dyes into harmless products (Eq. (10) and Eq. (11)) such as $\mathrm{CO}_{2}$ and $\mathrm{H}_{2} \mathrm{O}$. When the dosage of added $\mathrm{H}_{2} \mathrm{O}_{2}$ was above

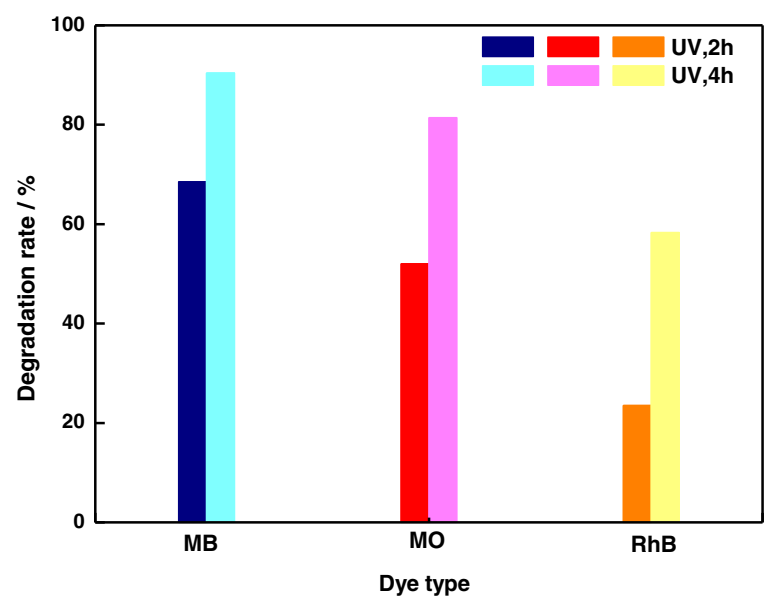

Fig. 12 The effects of dye type on degradation rate 
$0.24 \mathrm{~mol} / \mathrm{L}, \mathrm{H}_{2} \mathrm{O}_{2}$ made quenching reaction due to excess, i.e., $\mathrm{H}_{2} \mathrm{O}_{2}$ reacted with $\cdot \mathrm{OH}$ to form $\cdot \mathrm{OOH}$ (Eq. (12)) and the reaction (Eq. (13)) (Fayazi et al. 2016), thus reducing the degradation efficiency.

$\mathrm{H}_{2} \mathrm{O}_{2}+\mathrm{e}^{-} \rightarrow \mathrm{OH}^{-}+\cdot \mathrm{OH}$

$\mathrm{h}^{+}+\mathrm{OH}^{-} \rightarrow \cdot \mathrm{OH}$

$\mathrm{h}^{+}+\mathrm{H}_{2} \mathrm{O} \rightarrow \cdot \mathrm{OH}+\mathrm{H}^{+}$

$\mathrm{H}_{2} \mathrm{O}_{2}+\mathrm{h} v \rightarrow 2 \cdot \mathrm{OH}$

$\mathrm{OH}+$ dye $\rightarrow$ dye intermediate products

$\mathrm{OH}+$ dye intermediate products $\rightarrow$ harmless products

$\mathrm{H}_{2} \mathrm{O}_{2}+\cdot \mathrm{OH} \rightarrow \mathrm{H}_{2} \mathrm{O}+\cdot \mathrm{OOH}$

$\mathrm{OOH}+\cdot \mathrm{OH} \rightarrow \mathrm{H}_{2} \mathrm{O}+\mathrm{O}_{2}$

According to the curve of illumination for $4 \mathrm{~h}$ (unsealed), it could be seen that the degradation rate of MB solution kept increasing obviously with the increase of $\mathrm{H}_{2} \mathrm{O}_{2}$ dosage. This may be because the opening of the preservative film after $2 \mathrm{~h}$ of light would bring in air and promote the photocatalytic degradation.

Therefore, in the following work of this experiment, when studying the effect of UV-365 and $\mathrm{H}_{2} \mathrm{O}_{2}$ on other dyes, the optimal $\mathrm{H}_{2} \mathrm{O}_{2}$ dosage was $0.24 \mathrm{~mol} / \mathrm{L}$.

\subsubsection{Degradation Effect of $\mathrm{TiO}_{2} / \mathrm{CF}$ s on Different Dyes}

Figure 12 presents the effects of dye type on photocatalytic performance of $\mathrm{TiO}_{2} / \mathrm{CFs}$ under the conditions of UV-365 irradiation for $2 \mathrm{~h}$ and $4 \mathrm{~h}, \mathrm{TiO}_{2} / \mathrm{CFs}$ dosage of $4.8 \mathrm{~g} / \mathrm{L}$, dye concentration of $10 \mathrm{mg} / \mathrm{L}$, initial $\mathrm{pH}$ value of 7 , and $\mathrm{H}_{2} \mathrm{O}_{2}$ dosage of $0.24 \mathrm{~mol} / \mathrm{L}$. The degradation rates of $\mathrm{MB}, \mathrm{MO}$, and $\mathrm{RhB}$ were $68.5 \%, 52.0 \%$, and $23.5 \%$, respectively, when the irradiation time was $2 \mathrm{~h}$ (sealed). The degradation rate increased by $20-30 \%$ to $90.4 \%, 81.4 \%$, and $58.3 \%$ when the illumination time was further extended to $4 \mathrm{~h}$ (unsealed). Therefore, the prepared $\mathrm{TiO}_{2} / \mathrm{CFs}$ not only had excellent degradation effect on MB but also had certain degradation effect on $\mathrm{MO}$ and $\mathrm{RhB}$.

\section{Conclusion}

Anatase $\mathrm{TiO}_{2}$ was synthesized with uniform distribution and firm loaded in situ with CFs as carrier and TBT as raw material by the hydrothermal method and lowtemperature calcination. Therefore, the excellent photocatalytic performance of nano- $\mathrm{TiO}_{2}$ permanently endowed CFs. The photocatalytic properties of the prepared $\mathrm{TiO}_{2} / \mathrm{CFs}$ were tested by visible spectrophotometry. The results showed that $\mathrm{TiO}_{2} / \mathrm{CFs}$ had good degradation effects on $\mathrm{MB}, \mathrm{MO}$, and $\mathrm{RhB}$. The degradation rates of $\mathrm{MB}, \mathrm{MO}$, and $\mathrm{RhB}$ were $90.4 \%, 81.4 \%$, and $58.3 \%$, separately, at $\mathrm{TiO}_{2} / \mathrm{CFs}$ dosage of $4.8 \mathrm{~g} / \mathrm{L}$, initial dye concentration of $10 \mathrm{mg} / \mathrm{L}, \mathrm{pH}$ of 7 , and $\mathrm{H}_{2} \mathrm{O}_{2}$ dosage of $0.24 \mathrm{~mol} / \mathrm{L}$, after $4 \mathrm{~h}$ of UV-365 irradiation.

Funding Information The authors acknowledge the Scientific Research Fund of Taiyuan University of Technology for financial support (Project No. 20504020203) and Shanxi Provincial Foundation for Returned Scholars, China (Project No. 2017048).

\section{References}

Akpan, U. G., \& Hameed, B. H. (2009). Parameters affecting the photocatalytic degradation of dyes using $\mathrm{TiO}_{2}$-based photocatalysts: a review. Journal of Hazardous Materials, 170, 520-529.

Azeez, F., Al-Hetlani, E., Arafa, M., et al. (2018). The effect of surface charge on photocatalytic degradation of methylene blue dye using chargeable titania nanoparticles. Sci Rep-UK, 8, 7104 .

Cai, L. J., Li, Y. W., Li, Y. H., et al. (2018). Synthesis of zincphthalocyanine-based conjugated microporous polymers with rigid-linker as novel and green heterogeneous photocatalysts. Journal of Hazardous Materials, 348, 47-55.

Das, D., Sabaraya, I. V., Zhu, T., et al. (2018). Aggregation behavior of multiwalled carbon nanotube-titanium dioxide nanohybrids: probing the part-whole question. Environmental Science \& Technology, 52, 8233-8241.

Devipriya, S. P., \& Yesodharan, S. (2010). Photocatalytic degradation of phenol in water using $\mathrm{TiO}_{2}$ and $\mathrm{ZnO}$. Journal of Environmental Biology, 31, 247-249.

Fayazi, M., Taher, M. A., Afzali, D., et al. (2016). Enhanced Fenton-like degradation of methylene blue by magnetically activated carbon/hydrogen peroxide with hydroxylamine as Fenton enhancer. Journal of Molecular Liquids, 216, 781787. 
Giesz, P., Celichowski, G., Puchowicz, D., et al. (2016). Microwave-assisted $\mathrm{TiO}_{2}$ : anatase formation on cotton and viscose fabric surfaces. Cellulose, 23, 2143-2159.

Goudarzi, V., \& Shahabi-Ghahfarrokhi, I. (2018). Photoproducible and photo-degradable starch/TiO bionanocomposite as a food packaging material: development and characterization. International Journal of Biological Macromolecules, 106, 661-669.

John, N., Tharayil, N. J., \& Somaraj, M. (2017). Photocatalytic degradation of methyl orange using biologically enhanced tin oxide nanoparticles under UV-irradiation. Journal of Materials Science: Materials in Electronics, 28, 5860-5865.

Kaur, H., Kumar, S., Verma, N. K., et al. (2018). Role of pH on the photocatalytic activity of $\mathrm{TiO}_{2}$ tailored by W/T mole ratio. Journal of Materials Science: Materials in Electronics, 29, 16120-16135.

Kinsinger, N., Tantuccio, A., Sun, M. W., et al. (2011). Photocatalytic titanium dioxide composite. Journal of Nanoscience and Nanotechnology, 11, 7015-7021.

Liang, Y., Zhou, B., Li, N., et al. (2018). Enhanced dye photocatalysis and recycling abilities of semi-wrapped TiO2@ carbon nanofibers formed via foaming agent driving. Ceramics International, 44(2), 1711-1718.

Liu, X. H., Liu, Y., Lu, S. Y., et al. (2018). Performance and mechanism into $\mathrm{TiO}_{2}$ /zeolite composites for sulfadiazine adsorption and photodegradation. Chemical Engineering Journal, 350, 131-147.

Ma, J., Liu, Y., Ali, O., et al. (2018). Fast adsorption of heavy metal ions by waste cotton fabrics based double network hydrogel and influencing factors insight. Journal of Hazardous Materials, 344, 1034-1042.

Mishra, A., \& Butola, B. S. (2017). Deposition of Ag doped $\mathrm{TiO}_{2}$ on cotton fabric for wash durable UV protective and antibacterial properties at very low silver concentration. Cellulose, 24, 3555-3571.

Navarro, P., Sarasa, J., Sierra, D., et al. (2005). Degradation of wine industry wastewaters by photocatalytic advanced oxidation. Water Science and Technology, 51, 113-120.

Pensupa, N., Leu, S. Y., Hu, Y., et al. (2017). Recent trends in sustainable textile waste recycling methods: current situation and future prospects. Topics in Current Chemistry, 375, 76.

Phaltane, S. A., Vanalakar, S. A., Bhat, T. S., et al. (2017). Photocatalytic degradation of methylene blue by hydrothermally synthesized CZTS nanoparticles. Journal of Materials Science: Materials in Electronics, 28, 8186-8191.

Rauf, M. A., Meetani, M. A., \& Hisaindee, S. (2011). An overview on the photocatalytic degradation of azo dyes in the presence of $\mathrm{TiO}_{2}$ doped with selective transition metals. Desalination, 276, 13-27.

Sosnov, E. A., Trubina, T. S., \& Malygin, A. A. (2017). Chemical assembly of a titanium oxide layer on microporous silica. Russian Journal of General Chemistry, 87, 1786-1793.

Sun, Y. P., Guduru, R., Lin, F., et al. (2000). Preparation of nanoscale semiconductors through the rapid expansion of supercritical solution (RESS) into liquid solution. Industrial and Engineering Chemistry Research, 39, 4663-4669.

Tang, H. W., Ng, K. M., Chui, S. S. Y., et al. (2009). Analysis of melamine cyanurate in urine using matrix-assisted laser desorption/ionization mass spectrometry. Analytical Chemistry, 81, 3676-3682.

Vukoje, I., Kovač, T., Džunuzović, J. V., et al. (2016). Photocatalytic ability of visible-light-responsive $\mathrm{TiO}_{2}$ nanoparticles. Journal of Physical Chemistry C, 120, 1856018569.

Wang, W. J., Huang, G. C., Yu, J. C., et al. (2015). Advances in photocatalytic disinfection of bacteria: development of photocatalysts and mechanisms. Journal of Environmental Sciences (China), 34, 232-247.

Wu, D. Y., \& Long, M. C. (2011). Realizing visible-light-induced self-cleaning property of cotton through coating $\mathrm{N}-\mathrm{TiO}_{2}$ film and loading AgI particles. ACS Applied Materials \& Interfaces, 3, 4770-4774.

Xu, Z., Li, X., Wang, W., et al. (2016a). Microstructure and photocatalytic activity of electrospun carbon nanofibers decorated by $\mathrm{TiO}_{2}$ nanoparticles from hydrothermal reaction/ blended spinning. Ceramics International, 42(13), 1501215022.

Xu, Z., Wu, T., Shi, J., et al. (2016b). Photocatalytic antifouling PVDF ultrafiltration membranes based on synergy of graphene oxide and $\mathrm{TiO}_{2}$ for water treatment. Journal of Membrane Science, 520, 281-293.

Yang, M. P., Liu, W. Q., Jiang, C., et al. (2019). Robust fabrication of superhydrophobic and photocatalytic self-cleaning cotton textile based on $\mathrm{TiO}_{2}$ and fluoroalkylsilane. Journal of Materials Science, 54, 2079-2092.

Yusoff, M. M., Mamat, M. H., Malek, M. F., et al. (2016). Growth of titanium dioxide nanorod arrays through the aqueous chemical route under a novel and facile low-cost method. Materials Letters, 164, 294-298.

Zhang, H., \& Yang, L. (2012). Immobilization of nanoparticle titanium dioxide membrane on polyamide fabric by low temperature hydrothermal method. Thin Solid Films, 520, $5922-5927$.

Zhang, B., Maimaiti, H., Zhang, D. D., et al. (2017). Preparation of coal-based C-dots/ $/ \mathrm{TiO}_{2}$ and its visible-light photocatalytic characteristics for degradation of pulping black liquor. Journal of Photochemistry and Photobiology A, 345, 54-62.

Zhou, W. Y., Zhang, Y. Y., \& Shi, Y. D. (2017). In situ loading $\mathrm{TiO}_{2}$ and its photocatalysis and UV resistance on cotton fabric. Fibers and Polymers, 18, 1073-1078.

Publisher's Note Springer Nature remains neutral with regard to jurisdictional claims in published maps and institutional affiliations. 